University of Wollongong

Research Online

Faculty of Science, Medicine and Health -

Papers: Part B

Faculty of Science, Medicine and Health

$1-1-2018$

\title{
Variance in the response of silcrete to rapid heating complicates assumptions about past heat treatment methods
}

\author{
Alex Mackay \\ University of Wollongong, amackay@uow.edu.au \\ Sam C. Lin \\ University of Wollongong, samlin@uow.edu.au \\ Lachlan Kenna \\ University of Wollongong \\ Alex Blackwood \\ La Trobe University
}

Follow this and additional works at: https://ro.uow.edu.au/smhpapers1

\section{Publication Details Citation}

Mackay, A., Lin, S. C., Kenna, L., \& Blackwood, A. (2018). Variance in the response of silcrete to rapid heating complicates assumptions about past heat treatment methods. Faculty of Science, Medicine and Health - Papers: Part B. Retrieved from https://ro.uow.edu.au/smhpapers1/151 


\title{
Variance in the response of silcrete to rapid heating complicates assumptions about past heat treatment methods
}

\author{
Abstract \\ Heat treatment of silcretes in the Middle Stone Age of southern Africa has been taken to indicate \\ complex behaviour among early modern humans. This inference is based on the apparent sensitivity of \\ silcretes to rapid changes in temperature, requiring well-regulated heating and cooling rates, and controls \\ over maximum heating temperatures. Alternative arguments have been made that silcrete can effectively \\ be heat treated with limited control over heating rates such that heat treatment may have been a relatively \\ simple process. These apparently contrasting points of view elide the fact that different silcretes may \\ respond differently to heating, and that no single approach may be appropriate in all cases. To test this \\ proposition, we undertook a series of controlled experiments in which silcrete from two sources on the \\ south coast of Australia were prepared into blocks of specific sizes and heated rapidly to a range of \\ maximum temperatures in a muffle furnace. In addition to potential differences in response between \\ sources to heat, our experiments test two factors-stone volume and maximum heating temperature-that \\ were advanced by past explanatory models to account for the probability of sample failure (fracture) \\ during heating. The results of our experiments suggest that the tolerance of silcretes to high heating rates \\ is highly variable between sources within regions, and that the effect of variation between sources is \\ stronger than the other factors examined. Additional tests on limited samples from sources in South \\ Africa support the general relevance of our findings. From these results, we infer that optimal approaches \\ to heating in the past were probably sensitive to the silcretes being heated.

\section{Publication Details} \\ Mackay, A., Lin, S. C., Kenna, L. S. \& Blackwood, A. F. (2019). Variance in the response of silcrete to rapid \\ heating complicates assumptions about past heat treatment methods. Archaeological and \\ Anthropological Sciences, 11 (11), 5909-5920.
}


Mackay et al, Variance in the response of silcrete to rapid heating, Arch \& Anth Sci.

1 Variance in the response of silcrete to rapid heating complicates assumptions about past

2 heat treatment methods

3 Alex Mackay ${ }^{1,2}$, Sam C. Lin ${ }^{1,3}$, Lachlan S. Kenna ${ }^{1}$, Alex F. Blackwood ${ }^{4}$

$4 \quad{ }^{1}$ Centre for Archaeological Science, School of Earth and Environmental Sciences, University

5 of Wollongong, Wollongong, NSW, 2522, Australia; ${ }^{2}$ Department of Archaeology,

6 University of Cape Town, Rondebosch 7701, South Africa; ${ }^{3}$ Australian Research Council

7 Centre of Excellence for Australian Biodiversity and Heritage, University of Wollongong,

8 Wollongong, NSW, 2522, Australia; ${ }^{4}$ Department of Archaeology and History, La Trobe

9 University, Bundoora, VIC, 3086, Australia.

10 Abstract

11 Heat treatment of silcretes in the Middle Stone Age of southern Africa has been taken to 12 indicate complex behaviour among early modern humans. This inference is based on the 13 apparent sensitivity of silcretes to rapid changes in temperature, requiring well-regulated 14 heating and cooling rates, and controls over maximum heating temperatures. Alternative 15 arguments have been made that silcrete can effectively be heat treated with limited control 16 over heating rates such that heat treatment may have been a relatively simple process. These 17 apparently contrasting points of view elide the fact that different silcretes may respond 18 differently to heating, and that no single approach may be appropriate in all cases. To test this proposition, we undertook a series of controlled experiments in which silcrete from two sources on the south coast of Australia were prepared into blocks of specific sizes and heated rapidly to a range of maximum temperatures in a muffle furnace. In addition to potential differences in response between sources to heat, our experiments test two factors - stone volume and maximum heating temperature - that were advanced by past explanatory models to account for the probability of sample failure (fracture) during heating. The results of our experiments suggest that the tolerance of silcretes to high heating rates is dramatically variable between sources within regions, and that the effect of variation between sources is stronger than any of the other factors examined. Additional tests on limited samples from sources in South Africa support the relevance of our findings to other contexts of silcrete heating. From these results, we infer that optimal approaches to heating in the past were probably sensitive to the silcretes being heated. 
Mackay et al, Variance in the response of silcrete to rapid heating, Arch \& Anth Sci.

\section{Introduction}

The use of heat to alter the physical properties of siliceous rocks is a behavioural trait so far documented only among modern humans, and reasonably widespread in the global record. The apparently species-specific nature of this practice, coupled with underlying assumptions about the uniqueness of Homo sapiens' behavioural capabilities (Villa and Roebroeks 2014), has encouraged a perception that heat treatment reveals aspects of complexity in human cognition. Like many aspects of debates concerning the evolution of human behaviour, however, the link between evidence and inference is not straightforward. In this particular case, the link largely hinges on whether and to what extent effective heat treatment requires detailed planning, high initial costs with delayed-return benefits, and/or abstract reasoning (Brown et al. 2009; Wadley and Prinsloo 2014). Whether these elements are intrinsic to heat treatment is contested.

Current debate on heat treatment research and its implications for human behavioural evolution is guided by two different concepts of how the process was enacted. The earliest known use of heat treatment involved thermal alteration of the sedimentary rock silcrete and occurs in the southern African Middle Stone Age (Brown et al. 2009; Delagnes et al. 2016; Schmidt and Mackay 2016; Schmidt et al. 2013). Building on prior research, initial experiments to recreate that process worked on the assumption that successful heat treatment - that is, having the stone remain relatively intact after heating - required slow heating and cooling rates, and control over maximum temperatures (Brown et al. 2009). In order to achieve these controls, researchers buried silcrete blocks in an insulating medium (sand) before building a fire over the top. The fire was sustained for a period of hours before being allowed to burn out, and the sand was allowed to cool before the silcrete was extracted. Supporting research suggested that this insulated method was necessary to avoid the silcrete blocks fracturing, something which occurred regularly at higher temperatures in open fires (Wadley and Prinsloo 2014). This approach, which we might term 'high-cost', involves the planning and execution of hierarchical actions, and warrants many of the above-mentioned inferences regarding behavioural complexity.

An alternative 'low-cost' approach suggests that heat treatment can be carried out successfully when silcrete pieces are placed directly in an open fire (Schmidt et al. 2015a; 2017a). The underpinning principal is that, while slow heating/cooling rates and low maximum temperatures may be required for rocks such as chert and flint, the greater porosity of silcrete enables it to withstand both greater heating/cooling rates and higher maximum temperatures (Schmidt 2014; Schmidt et al. 2017b). Experimental and ethnographic observations on the heating of other rock types may thus not be relevant to the process as it applies to silcrete. In support of this proposition is evidence for carbonised green wood exudates (residues) on heated silcretes from archaeological sites in southern Africa, along with frequent evidence for heat fracture prior to flaking that, as noted above, is difficult to reconcile with an insulated or 'sand-bath' heating technique (Delagnes et al. 2016; Schmidt et al. 2015a, 2017a). It has also been noted that there is no ethnographic evidence that the sandbath approach was ever used during heating of silcrete (Schmidt 2016). If this 'low-cost' approach is a more accurate characterisation of typical silcrete heat treatment in the past, then 
Mackay et al, Variance in the response of silcrete to rapid heating, Arch \& Anth Sci.

the implications for behavioural complexity are probably quite limited. While the process is transformative, it is not necessarily any more conceptually complex than cooking food.

One potential complication to past experimental work in this debate is the tendency to treat silcrete as a coherent class of rock that is likely to respond consistently to heating. Yet, silcrete is heterogeneous in formation, composition and character (Roberts 2003; Summerfield 1981), and responses to heating have been demonstrated to be variable at regional scales (Schmidt et al. 2017c; note also Byers et al. 2014 with respect to chert). Developing reasonable expectations for the practice of silcrete heat treatment in the past thus requires some understanding of the range of variation in tolerance for different heating rates and maximum temperatures between samples from difference sources. Indeed, it seems plausible that both the high-cost and low-cost approaches outlined above may be viable for different silcretes, given sufficient variation in response.

To begin to address this problem, we undertook a set of controlled experiments on silcrete samples from two nearby sources located on the east coast of New South Wales (NSW), Australia. Our objective with these experiments was principally to explore the extent of intersource variation on the response of silcretes to rapid heating. These controlled experiments emerged from a series of actualistic (camp fire) experiments carried out with silcretes from three sources around the site of Varsche Rivier 003 (VR003) in South Africa (Steele et al. 2016). In those early trials we observed differences in fracture rates between sources during individual heating runs. We had intended to conduct subsequent formal controlled experiments on samples from the same sources but lacked sufficient material for multiple replications with different factors (as described below). We thus switched to the NSW sources as they were easy to access - providing enough material for multiple replications and because both are known to have been used archaeologically (Hanckel 1985; Hughes et al. 1973). While our results focus on the NSW samples, we provide a brief discussion of the results from limited controlled experiments on a small sample of South African silcretes for comparative purposes.

\section{Controls on fracture during heating of silcrete}

A range of controls on the probability of fracture during heating of silcrete have been identified by past research, including porosity, heating rate, nodule volume, maximum temperature, mineralogy, and mineral phase change (Wadley and Prinsloo 2014; Schmidt et al. 2017b; Schmidt 2014; Mercieca and Hiscock 2008; Kenna 2016). In this paper we do not undertake any mineralogical analysis but concentrate on the effects of two factors - heat and volume - on the probability and extent of silcrete fracture during heating. We focus on rapid heating because the tolerance of silcrete to steep temperature gradients is, along with maximum temperature tolerated, one of the key elements of the current debate.

In a classic and influential set of controlled experiments, Mercieca and Hiscock (2008) explored how silcrete blocks of different volumes respond when exposed to different maximum temperatures. In their experiments, blocks were cut into consistent shapes (cubes) and placed in a preheated furnace, producing very steep temperature gradients. Their results 
Mackay et al, Variance in the response of silcrete to rapid heating, Arch \& Anth Sci.

differentiated three zones of response - intact, cracking and fracture (Figure 1). In the intact zone, blocks had no visually-noticeable adverse effects from heating. In the cracking zone, blocks had visually-noticeable cracks but remain coherent. The fractured blocks broke apart. Probability of cracking and fracturing both increased in response to maximum temperature and block volume, such that smaller blocks were able to withstand higher maximum temperatures prior to cracking/fracturing than larger blocks. In general, no cracking or fracturing was witnessed below $600^{\circ} \mathrm{C}$, and in the smallest blocks, temperatures of up to $700^{\circ} \mathrm{C}$ could be tolerated without cracking.

The Mercieca and Hiscock (2008) experiments established that silcretes can tolerate high heating rates without fracturing, albeit more easily when volumes are small. They did not speculate on the underlying mineralogical or chemical causes of this pattern; nevertheless the results stand in contrast to other statements that have been made with respect to temperature controls. In a set of actualistic experiments, for example, Wadley and Prinsloo (2014) noted that blocks heated to $\geq 573^{\circ}$ - either in an open fire or on a bed of coals - invariably fractured, while those heated to $\leq 521^{\circ} \mathrm{C}$ - whether on a bed of coals or buried in sand beneath the fire did not. Ascribing this pattern to energy release during a phase change in quartz minerals, Wadley and Prinsloo (2014: 49) concluded that: "Rapid heating or cooling through the phase transformation at $573^{\circ} \mathrm{C}$ will cause fracture of the silcrete". Their results suggest that, size effects notwithstanding, the propensity of silcrete to shatter will increase around and beyond that value.

A limitation common to both of these sets of experiments is that they used silcrete from singular sources to generate general statements about controls on fracture. Yet as Schmidt et al. (2017c) demonstrate, different silcretes may respond quite differently when heated, complicating the formulation of general response curves. In order to explore this idea further we set up a series of controlled experiments modelled on Mercieca and Hiscock's (2008) work, testing the effect of volume and maximum temperature on probability of fracture under conditions of rapid heating. In contrast to earlier experiments, however, we used silcrete from multiple sources, including one of the sources (Bannisters Point) used by Mercieca and Hiscock (2008). Our interest here is not to test the validity of earlier results, but their universality. More specifically we ask: To what extent do silcretes from different sources exhibit similar responses to rapid heating when volume and maximum temperature are controlled for?

We should note at the outset that our experiments only tested for the probability of visuallynoticeable fracture. It is plausible that unfractured rocks could sustain sufficient damage to their internal structure as to be unusable for tool production, and equally that fractured blocks were otherwise fine for knapping. Those consequences of heating were not explored in those experiments.

\section{Material and Methods}

\section{Australian (NSW) samples}


Mackay et al, Variance in the response of silcrete to rapid heating, Arch \& Anth Sci.

Silcrete samples were collected from two outcrop sources in NSW: Bendalong Point (BDL) and Bannisters Point (BNS) (Figure 2). The latter is the same source used by Mercieca and Hiscock (2008). The two sources are in close proximity from each other $(\sim 10 \mathrm{~km})$ and are both associated with the deeply weathered Tertiary sediments in the Bendalong-Ulladulla area (Hughes et al. 1973; Young and McDougall 1982). The silcrete in this area is generally grey in colour and composed of poorly-sorted quartz clasts set in a fine-grained authigenic quart cement (Challender 1978 cited in Young and McDougall 1982). Multiple large nodules ( $40 \mathrm{~cm}$ in maximum dimension) were collected from the two sources; stones with dissimilar colour and cortex were purposely included to maximise the variation represented in each source.

Three nodules from each source with suitable morphology for cutting were selected for sample preparation. Each nodule was cut into 60 cubes of four different volumes (15 cubes per volume): $1 \times 1 \times 1 \mathrm{~cm}\left(1 \mathrm{~cm}^{3}\right), 2 \times 2 \times 2 \mathrm{~cm}\left(8 \mathrm{~cm}^{3}\right), 3 \times 3 \times 3 \mathrm{~cm}\left(27 \mathrm{~cm}^{3}\right)$, and $4 \times 4 \times 4 \mathrm{~cm}(64$ $\left.\mathrm{cm}^{3}\right)$. These four volume designs cover the size range used by Mercieca and Hiscock (2008) and allow us to evaluate the effects of volume at given heating temperatures. Importantly, by preparing the samples with the standard cube shape, we hold the effect of sample shape constant and thus isolate the influence of volume. The cubes were cut by a brick saw with a diamond blade and refined by a trim saw if necessary. Each sample was weighed to the nearest $0.1 \mathrm{~g}$. Based on visual inspection of the cut surfaces, all of the samples had similar lithological properties, being composed mainly of matrix with some notable grains, and could be classified as 'floating fabric' according to Summerfield (1981).

The silcrete samples were heated in an electrical muffle furnace preheated to three set temperatures: $550^{\circ} \mathrm{C}, 600^{\circ} \mathrm{C}$, and $700^{\circ} \mathrm{C}$. Five samples per volume per parent nodule from each source were heated at every temperature level. This factorial design allows an equal spread of observations across all possible combinations of the independent variables. Such an approach involves trade-offs. In the case of explosive fracture (see below) it is not always possible to recover all of the fragments of the original block, and detail is necessarily lost. Furthermore, adding multiple blocks involves leaving the furnace door open for a longer period than when single specimens are heated, and the addition of different total volumes in each heating run may also impact the heat within the furnace. While we did not attempt to document the effects of these factors (furnace opening times and volume added) on starting temperature, in all cases the furnace temperatures returned quickly to the selected maximum. The benefit of this approach is to allow multiple replications, with less reliance on the representativeness of single specimens.

Following Mercieca and Hiscock's (2008) results , our samples should remain intact regardless of their size after heating to either $550^{\circ} \mathrm{C}$ or $600^{\circ} \mathrm{C}$. When heated to $700^{\circ} \mathrm{C}$, however, we would expect samples with greater volume to experience more heat fracture than those of smaller volumes. In contrast, following Wadley and Prinsloo, our, samples heated to $550^{\circ} \mathrm{C}$ should largely remain intact, while those heated to temperatures above $573^{\circ} \mathrm{C}$ should exhibit much higher rates of heat-induced cracking or fracture.As the furnace was preheated, and the samples taken from room temperature, heating rates were rapid in all cases - this is a variable we do not explicitly explore here. The samples were positioned in 
Mackay et al, Variance in the response of silcrete to rapid heating, Arch \& Anth Sci.

the furnace according to a predetermined arrangement with gaps in between samples so they did not have contact with each other. Each heating event included samples from all size groups. In this way, any variation among the heating episodes was spread across the different volume categories and would not bias particular size levels. The locations of samples of different sizes within the furnace were randomised to ensure that there were no confounding effects from zones of variable temperature within the heated area. All samples were heated for one hour before the furnace was turned off to allow the stones to cool gradually; one hour is sufficient for major heat-induced mineralogical transformations in chert and flint (Schmidt et al., 2015b). This gradual cooling procedure limits the occurrence of fractures caused by rapid cooling. The furnace was not opened until its temperature had fallen back to ambient. After heating, the samples were retrieved from the furnace and weighed. If a sample was fractured (broken with largest remaining fragment $\geq 50 \%$ of original mass) or exploded ( $<50 \%$ of original mass), the largest remaining piece was identified, based on the sample's original placement location, and weighed. If samples could not be found, we took this as an indication of severe heat fracture and noted the remaining sample weight as zero.

To quantify the extent of heat fracture, we computed the percentage of surviving mass for each sample by dividing the post-heating weight by the pre-heating weight. If the postheating sample weight is zero because no remaining pieces were found, we marked the percentage as zero. This measure, however, has some uncertainties. Namely, samples experiencing similar levels of heat fracture could have dissimilar post-heating weight due to the influence of fabric arrangements and incipient faults/fractures on fracture pathways $-\mathrm{a}$ fracture through the centre of a sample would result in a 50\% surviving mass while a fracture closer to the edge would result in a greater percentage of surviving mass. Thus, treating the percentage of surviving mass as a continuous measure could misrepresent the actual degree of heat fracture represented among the samples. To minimise the impact of this uncertainty, we classified the percentages into three arbitrary intervals defined to reflect varying states of heat fracture: 0-49\% (“exploded"), 50-89\% (“fractured"), and 90-100\% ("survived").

We constructed a cumulative link model to evaluate the effect of temperature, sample volume, and source on the heat fracture categories. A cumulative link model, or an ordinal regression model, is a type of generalized linear model for handling ordinal response variables where the distance among the variable categories are unknown (Agresti 2007; Christensen 2015a). For this study, although the distances among the three heat fracture intervals are known (as we defined them), the variable was treated at an ordinal scale (survived $>$ fractured $>$ exploded) for the purpose of model building. We used a proportional odds model which includes a logit link to describe the log odds of the probabilities for observations falling in a lower category versus the remaining higher categories (Agresti 2007; Christensen 2015a). The model produces a set of coefficients describing the effect of predictor variables (temperature, volume, and source) on the response variable (heat fracture extent) and two intercepts that mark the thresholds separating the three response categories.

Model fitting was conducted using the R statistical software (R Core Team 2017) and the 'ordinal' package (Christensen 2015b). The clm function from 'ordinal' was used to 
Mackay et al, Variance in the response of silcrete to rapid heating, Arch \& Anth Sci.

construct the proportional odds model; the nominal_test function from the same package was used to perform a likelihood ratio test (Barr et al. 2013) for the proportional odds assumption where the influence of the predictors is assumed to be consistent across different thresholds of heat fracture (Christensen 2015b). The two predictor variables are transformed to $\mathrm{z}$ scores to improve their interpretability. We consider all two-way interactions among the three predictors. Based on the observations of Mercieca and Hiscock (2008), we expect an interaction between volume and temperature, that is, the effect of temperature on heat fracture should be conditioned by sample volume. The significance for each interaction is tested by using a likelihood ratio test. We further check the stability of the overall model by computing the $90 \%$ confidence intervals for the model coefficients with a 2-fold cross validation over 1000 iterations. Additional R packages of ggplot2 (Wickham 2009), scales (Wickham 2017) and reshape2 (Wickham 2007) were used for data presentation. An alpha level of 0.05 is employed to assess the level of significance here and the tests hereafter.

We also tested the proposition that rates of fracture would increase significantly for samples heated above $573^{\circ} \mathrm{C}$ by employing a linear-by-linear association test (Agresti 2007). The linear-by-linear test, implemented in the R statistical software package with the $l b l$ test function from the coin package (Hothorn et al. 2008), assesses the association between ordered categorical variables.

\section{South African (VR003) samples}

For the controlled experiments on South African silcretes, we used samples collected from three sources within $20 \mathrm{~km}$ of the archaeological site of VR003 located in southern Namaqualand (Figure 2). All three sources appear to have been exploited in the Middle Stone Age - that is, all three have Middle Stone Age artefact scatters associated with them - and macroscopic characteristics suggest that artefacts from these sources were transported to VR003. The sources occur in Tertiary and Quaternary sands of the Knersvlakte region and include matrix-supported (Olifants River source), floating fabric (Mustard Hill source) and grain-supported (Quartz Valley source) fabric types (Roberts 2003). Sorting in these silcretes is moderate to poor, with subangular quartz inclusions up to $3 \mathrm{~mm}$.

As with the NSW sample, nodules were cut into cubes using a brick saw and refined with a trim saw, and weighed to $0.1 \mathrm{~g}$. Due to the limited material available, we were only able to prepare three cubes for each source in the $27 \mathrm{~cm}^{3}$ and $64 \mathrm{~cm}^{3}$ volumes, and nine in the $1 \mathrm{~cm}^{3}$ volume. We did not prepare any cubes of $8 \mathrm{~cm}^{3}$. Samples were placed in the same electrical muffle furnace preheated to $550^{\circ} \mathrm{C}, 600^{\circ} \mathrm{C}$, and $700^{\circ} \mathrm{C}$. Given the three test temperatures and the small number of cubes we could cut, this equated to one sample per source per temperature at each of $27 \mathrm{~cm}^{3}$ and $64 \mathrm{~cm}^{3}$, and three samples per source per temperature at 1 $\mathrm{cm}^{3}$.

To enhance the reproducibility of our results and to improve research transparency, we include the R code (in R Markdown format) and data as supplemental material. The code and data are released under the CC-BY licence (see Marwick 2017).

\section{Results}


Mackay et al, Variance in the response of silcrete to rapid heating, Arch \& Anth Sci.

\section{Australian (NSW) samples}

Table 1 outlines the percentage of surviving mass for each sample after heating; Figure 3 summarises the proportions of the three fracture categories by temperature and volume. Looking at Figure 3, there is a clear difference between the two sources in the extent of heat fracture. Most of the BDL samples survived with minimal or no mass lost. There also appears to be some association between volume and heat fracture if the smallest volume group (1 $\mathrm{cm}^{3}$ ) is excluded. However, even by doing so, the actual difference of heat fracture frequency among the three larger volume groups is minimal. Similarly, while there seems to be an association between temperature and heat fracture, the difference is again quite small. Interestingly, the BDL samples that shattered completely (i.e., 0\% remaining mass) are all from the $1 \mathrm{~cm}^{3}$ volume group (Table 1). This outcome could suggest that heat fracture breaks up entire samples more easily when volume is small, which explains why there is a lack of 'fractured' samples in this size category. However, this pattern could also relate to sample recovery error. Specifically, since these samples are small to begin with, the fractured fragments can scatter more easily inside the furnace. If this is the case, the post-heating sample could be difficult to identify, and thus the weight of the surviving sample would be assumed to be zero.

In comparison to BDL, the rate of heat fracture among BNS samples is much higher. Over half of the BNS samples in the $27 \mathrm{~cm}^{3}$ group are 'fractured' and 'exploded', meaning they have lost more than $10 \%$ of their original weight; for the $64 \mathrm{~cm}^{3}$ group, close to $70 \%$ of the samples lost more than $50 \%$ of their original mass. The association between sample volume and heat fracture is also clearer among the BNS samples, where the number of 'fractured' and 'exploded' samples increases considerably with volume. There is, however, no clear relationship between temperature and heat fracture. Again, all of the 'exploded' samples in the $1 \mathrm{~cm}^{3}$ group have $0 \%$ surviving mass - this could be due to the sample recovery error discussed above. That said, there are also samples in the larger volume groups with $0 \%$ mass remaining. These cases are more likely to represent severe heat fracture where the samples were severely fragmented by heat and became unidentifiable.

Turning to the proportional odds model, likelihood ratio test for all two-way interactions by single term deletion returned significant outcome for the interaction between volume and source (Likelihood ratio test: LR stats $=6.35, \mathrm{df}=1, \mathrm{p}=0.012$ ). On the other hand, no notable interactive effect is detected between temperature and sample volume (Likelihood ratio test: LR stats $=0.018, \mathrm{df}=1, \mathrm{p}=0.89$ ), nor between temperature and source (Likelihood ratio test: LR stats $=0.13, \mathrm{df}=1, \mathrm{p}=0.72$ ). A single term addition analysis also returned identical results, with only the interaction between volume and source being significant (Likelihood ratio test: LR stats $=6.41, \mathrm{df}=1, \mathrm{p}=0.011$ ). We drop the two non-significant interaction terms from the model to avoid overfitting. Table 2 summarises the model. All of the coefficients fall within their respective $90 \%$ confidence interval derived from cross validation. The model suggests that temperature does not have a significant effect on sample heat fracture.

The interaction between volume and heat fracture captures the different relationship between the two variables across the two sources. Looking at Figure 3, the relationship between 
Mackay et al, Variance in the response of silcrete to rapid heating, Arch \& Anth Sci.

volume and heat fracture appears to be non-linear among the BDL samples, where the frequency of samples experiencing greater heat fracture declines with volume when samples are small $\left(1-8 \mathrm{~cm}^{3}\right)$ but increases when samples becomes bigger $\left(8-64 \mathrm{~cm}^{3}\right)$. On the other hand, the same relationship among the BNS samples is linear, with the number of heat fractured samples as well as the extent of fracture both rise with volume.

While the inter-source difference in the effect of volume is intriguing, there exists the possibility that the $1 \mathrm{~cm}^{3}$ samples are not directly comparable to other size groups due to the issues of recovery bias and the overrepresentation of 'exploded' pieces as discussed earlier. For this reason, we constructed a second proportional odds model by excluding the smallest size group to see how the remaining samples behave. The results indicate that, among the 8$64 \mathrm{~cm}^{3}$ samples, the interaction between source and volume is not significant (Likelihood ratio test: $\mathrm{LR}$ stats $=2.33, \mathrm{df}=1, \mathrm{p}=0.13$ ). This difference makes sense as the non-linear relationship between volume and heat fracture among the BDL samples observed earlier was driven largely by the $1 \mathrm{~cm}^{3}$ samples. After excluding the non-significant interaction term, the model (Table 4) suggests that both volume and source have significant independent influence over the degree of heat fracture among the samples.

Based on the second model that excludes the $1 \mathrm{~cm}^{3}$ samples, Figure 4 summarises the modelled effects of volume and source on heat fracture. In essence, greater stone volume leads to heightened probability for heat fracture to occur (and hence lowers the chance for the samples to remain intact or "survived"). While this effect is present in both sources, the actual probability for heat fracture is offset by inter-source variation. Namely, the degree of heat fracture is overall quite low among the BDL silcrete. Even for the $64 \mathrm{~cm}^{3}$ group where the effect of volume on heat fracture is the greatest, the BDL silcrete has around 70\% chance of remaining relatively intact (i.e., losing only up to $10 \%$ of original weight to heat fracture). On the other hand, the degree of heat fracture is notably higher for BNS silcrete. As sample volume increases, the probability for substantial fracture (losing up to 50-100\% of original weight) to occur rises sharply. Looking at the $64 \mathrm{~cm}^{3}$ group again, the BNS samples have only $18 \%$ chance of staying intact but $64 \%$ chance of becoming "exploded". In summary, while the influence of stone volume on the extent of heat fracture holds for both BDL and BSN silcrete, the two sources exhibit different tolerance to rapid heating. Overall, BSN silcrete has a greater probability for heat-induced fracture than BDL silcrete. Interestingly, the chance for BNS samples to become "fractured" is relatively stable across different volumes. This could be explained by the fact that, because BNS silcrete is less resistant to heat fracture, when samples experience heat fracture, particularly those in the larger size groups, they are more likely to become "exploded" rather than "fractured"-i.e., if heat fracture occurs, the larger stones are more likely to suffer greater fragmentation.

Table 3 represents the contingency table of heat fracture categories and temperatures that fall above and below $573^{\circ} \mathrm{C}$. The linear-by-linear association test returned a non-significant result $(\mathrm{Z}=-0.158 ; \mathrm{p}=0.87$ ), indicating that the extent of heat fracture is independent of temperatures being above or below $573^{\circ} \mathrm{C}$. 
Mackay et al, Variance in the response of silcrete to rapid heating, Arch \& Anth Sci.

Comparing our results to previous findings, our model supports the observation that stone volume influences the occurrence and extent of heat-induced fracture. Importantly, in addition to the effect of stone volume, the model also indicates that inter-source variation plays an important role in dictating the likelihood for heat fracture to occur. Overall, the BDL silcrete exhibits much greater resistance to heat-induced fracture than the BNS silcrete. Furthermore, contrary to expectation, temperature does not influence silcrete heat fracture among the samples tested here - at least, not once temperatures are $>550^{\circ} \mathrm{C}$. This outcome remains true even if we only include samples from BNS, which is the same silcrete source examined by Mercieca and Hiscock (2008) (see Appendix). Overall, we found no support for the proposition that heating beyond $573^{\circ} \mathrm{C}$ significantly effects the general probability of fracture.

\section{South African (VR003) samples}

The small sample size and lack of replications at the larger volumes necessitates cautious treatment of our experiments on South African material. For this reason we present descriptive results only. However the results allow an examination of whether inter-source variation is likely to be a common feature in the response of different silcretes to heating. As such, our data on South African silcretes provides clearer implications for the debates we discussed at the start of this paper. Here we focus solely on whether there appear to be differences in responses to rapid heating between sources, as suggested by our initial camp fire experiments, and subsequently demonstrated using NSW samples under controlled experimental conditions.

The proportions of the three fracture categories by temperature and volume are summarised in Figure 5. As with the NSW examples, samples from the different South African sources appear to fracture at quite different rates overall. None of the floating fabric samples from Mustard Hill fractured at any temperatures at any volume. A single $1 \mathrm{~cm}^{3}$ cube of grainsupported material from Quartz Valley exploded at $700^{\circ} \mathrm{C}$, and a $27 \mathrm{~cm}^{3}$ cube fractured at $550^{\circ} \mathrm{C}$; none of the $64 \mathrm{~cm}^{3}$ cubes from this source fractured at any temperature. In contrast, the matrix-supported silcretes from the Olifants River source exploded at all volumes and at all temperatures. All three of the $64 \mathrm{~cm}^{3}$ cubes exploded, while two of the $27 \mathrm{~cm}^{3}$ cubes exploded and the remaining cube fractured. Survivorship was documented among the $1 \mathrm{~cm}^{3}$ cubes only, though the number of replications here was larger.

\section{Discussion and Conclusions}

Heat treatment of siliceous rocks prior to knapping has a reasonably long history of research, albeit generally of low intensity. That intensity of research has recently increased in response to the argument that the appearance of heat treatment may carry implications for the evolution of human behaviour. As noted at the outset, the validity of those implications largely depends on how heat treatment was conducted in the deeper past, and whether the underlying process was elaborate, with high set up costs, delayed returns, and significant sensitivities to variation in heating parameters, or whether the process was expedient, and with relatively low sensitivities. 
Mackay et al, Variance in the response of silcrete to rapid heating, Arch \& Anth Sci.

Our purpose with this experimental program was not to resolve those debates, but to explore whether there may be flaws in one of its assumptions - namely that responses of silcrete to heating are consistent, such that valid general statements could be made about the likely way in which heat treatment was conducted in the past. Some past work suggests that this assumption is problematic (Schmidt et al. 2017c), and our results here appear to confirm this. In our principal set of experiments, using silcrete from two sources located not far from one another, we found quite dramatic differences in response to rapid heating. One source (Bannisters Point) exhibited much lower tolerance to rapid heating than the other (Bendalong), to the extent that inter-source variation had a stronger effect on the probability of fracture than either of the other established factors that we tested. These results are supported by experiments on South African silcretes known to have been used during the Middle Stone Age. With exceptions as discussed below, it thus seems to us unreasonable to make claims about the way silcrete per se responds to rapid heating without first understanding the causes for the difference in heat response among sources.

Our results support some elements of past research but not others. In our tested samples, increasing the volume of the pieces increases the probability that they will fracture when rapidly heated. However, given that we included samples from the same source as Mercieca and Hiscock (2008), this finding does not constitute fully independent support for that proposition. Perhaps more surprisingly, we found no significant effect of maximum temperature on probability of fracture in our NSW samples. This is at odds with expectations from both the volume-temperature interaction model, but also with the suggestion that heating to or beyond $573^{\circ} \mathrm{C}$ increases fracture probability.

Necessarily our experiments have limitations. We did not explicitly explore different heating rates, and data recovery was not equivalent between samples of all volumes. Our controlled experiments with South African samples were quite limited. Furthermore we have not made any attempt to explain the observed variation in response between our sources - whether water content, porosity, or mineralogy differed between sources in ways that might account for their starkly differing probability of fracture. Such research would be valuable for generating prior predictions about the ways any given silcrete might respond to heating. To the extent that this is possible, it would be a more sound basis for generalised statements.

Perhaps a more important limitation is one that is not particular to our research, but which is fairly pervasive, and that is the assumed association between fracture and failure. As we noted early, the fact that a given block survived heating to $700^{\circ} \mathrm{C}$ has few necessary behavioural implications. The surviving block, though coherent, could be unworkable, and the opposite could hold for blocks that fractured. It is thus important to move beyond the failure concept to quantify the benefits obtained by heat treatment, such as changes such as flake size and frequency of abrupt terminations (Crabtree and Butler 1964; Mandeville and Flenniken, 1974). Controlled experiments conducted by Byers et al (2014) are noteworthy in this respect. Comparing two different chert types available in the same secondary deposits, they found not only different sensitivities to fracture during heating, but that the quantifiable change in flaking properties was also markedly different between the two types (ie., one chert 
Mackay et al, Variance in the response of silcrete to rapid heating, Arch \& Anth Sci.

440 displayed greater benefit from heating than the other). The benefit obtained by heating can

441 thus be different between types within a raw material class.

442 Given that both costs (in the form of heating controls, modulated by raw material

443 sensitivities) and benefits (in the form of changes in flaking characteristics) of heat treatment

444 can vary, the dichotomy discussed at the start of this paper may be invalid. Silcretes that

445 display high tolerance to rapid heating might most efficiently be heated quickly, while those

446 more sensitive to heating might require greater control over heating rates. But in either case

447 how much time/effort should be invested in heating will be constrained by an assessment of

448 the resulting payoff. This raises the interesting possibility that more than one heat treatment

449 strategy may have been employed, either through time in response to changing technological

450 requirements, or at a given time in response to the tolerances of different sources. Evidence

451 for cognitive complexity might thus not reside in the application of any one approach to heat

452 treatment, but in flexible behavioural responses that are sensitive to such variation.

\section{Acknowledgements}

454 AM's research was funded by an Australian Research Council DECRA grant

455 (DE130100068). Identification of sources around Varsche Rivier 003 and our campfire

456 experiments occurred during the project "Varsche Rivier 003: A new Middle Stone Age site

457 (Namaqualand, South Africa)" funded by a National Research Foundation grant (Award

$458 \# 1324719)$ to Teresa E. Steele. We thanks Prof. Steele for enabling this research. 
Mackay et al, Variance in the response of silcrete to rapid heating, Arch \& Anth Sci.

461

462

463

464

465

466

467

468

469

470

471

472

473

474

475

476

477

478

479

480

481

482

483

484

485

486

487

488

489

490

491

492

493

494

495

496

\section{References}

Agresti A (2007) An introduction to categorial data analysis, $2^{\text {nd }}$ ed. John Wiley \& Sons, Inc, Hoboken.

Barr DJ, Levy R, Scheepers C, Tily HJ (2013) Random effects structure for confirmatory hypothesis testing: Keep it maximal. J Mem Lang 68:255-278.

Brown KS, Marean CW, Herries AIR, Jacobs Z, Tribolo C, Braun D, Roberts DL, Meyer MC, Bernatchez J (2009) Fire as an engineering tool of early modern humans. Science 325:859-62.

Byers DA, Picka C, Ray JH (2014). Heat treatment, Ozarks cherts, and prehistoric toolstone use in southwest Missouri. American Antiquity 79: 507-521.

Calender JH (1978) A study of silcretes near Marulan and Milton, New South Wales. In:LangfordSmith T (ed) Silcrete in Australia. University of New England, Armidale, pp 209-222.

Christensen RHB (2015a) Analysis of ordinal data with cumulative link models - estimation with the R-package ordinal. https://cran.r-project.org/web/packages/ordinal/vignettes/clm_intro.pdf

Christensen RHB (2015) ordinal - Regression Models for Ordinal Data. R package version 2015.6-28. http://www.cran.r-project.org/package=ordinal/.

Crabtree DE, Butler BR (1964) Notes on experiments in flintknapping 1: Heat treatment of silica minerals. Tebiwa 7: 1-6

Delagnes A, Schmidt P, Douze K, Wurz S, Bellot-Gurlet L, Conard NJ, Nickel KG, van Niekerk KL, Henshilwood CS (2016) Early evidence for the extensive heat treatment of silcrete in the Howiesons Poort at Klipdrift Shelter (Layer PBD, 65 ka), South Africa. PLoS One 11:e0163874.

Dillian C (2016) Heat treatment of Pennsylvania jasper. North American Archaeologist 2: 138-161

Hanckel M (1985) Hot rocks: Heat treatment at Burrill Lake and Currarong. Archaeol Ocean 20:98103.

Hothorn T, Hornik K, van de Wiel MA, Zeileis A (2008). Implementing a class of permutation tests: The coin package. J Stat Softw 28:1-23.

Hughes PJ, Sullivan ME, Lampert RJ (1973) The use of silcrete by Aborigines in southern coastal NSW. Archaeol Ocean 8:220-225.

Kenna LS (2016) Understanding intra-source and inter-source variation on the success of silcrete heat treatment. School of Earth and Environmental Sciences, University of Wollongong.

Mandeville MD, Flenniken JJ (1974) A comparison of the flaking qualities of Nehawka

Marwick B (2017). Computational reproducibility in archaeological research: Basic principles and a case study of their implementation. J Archaeol Method Th 24:424-450.

Mercieca A, Hiscock P (2008) Experimental insights into alternative strategies of lithic heat treatment. J Archaeol Sci 35:2634-2639.

Prinsloo LC, van der Merwe EM, Wadley L (2017) The thermal behaviour of silica varieties used for tool making in the Stone Age. J Therm Anal Calorim https://doi.org/10.1007/s10973-017-6602-Z 
Mackay et al, Variance in the response of silcrete to rapid heating, Arch \& Anth Sci.

497 R Core Team (2017) R: A language and environment for statistical computing. R Foundation for

498 Statistical Computing, Vienna, Austria. https://www.R-project.org/.

499 Roberts DL (2003) Age, genesis and significance of South African coastal belt silcretes. Vol. 95.

500 Council for Geoscience, South Africa.

501 Schmidt P (2014) What causes failure (overheating) during lithic heat treatment? Archaeol Anthropol

502 Sci 6:107-112.

503 Schmidt P (2016) The 'sand-bath' and lithic heat treatment in the South African Middle Stone Age:

504 Myth or reality? Afr Archaeol Rev 33:99-105.

505 Schmidt P, Porraz G, Slodczyk A, Bellot-Gurlet L, Archer W, Miller CE (2013) Heat treatment in the

506 South African Middle Stone Age: temperature induced transformations of silcrete and their

507 technological implications. J Archaeol Sci 40:3519-3531.

508 Schmidt P, Porraz G, Bellot-Gurlet L, February E, Ligouis B, Paris C, Texier P, Parkington JE, Miller 509 CE, Nickel KG, Conard NJ (2015a) A previously undescribed organic residue sheds light on heat 510 treatment in the Middle Stone Age. J Hum Evol 85:22-34.

511 Schmidt P, Mackay A (2016) Why was silcrete heat-treated in the Middle Stone Age? An early 512 transformative technology in the context of raw material use at Mertenhof Rock Shelter, South Africa.

513 Plos One 11:e0149243.

514 Schmidt P, February E, Bretzke K, Bellot-Gurlet L (2017a) Tempering-residue on heat-treated 515 silcrete: an experimental perspective and a potential analytical protocol. J Archaeol Sci: Reports 516 15:611-619.

517 Schmidt P, Lauer C, Buck G, Miller CE, Nickel KG (2017b) Detailed near-infrared study of the 518 'water'-related transformations in silcrete upon heat treatment. Phys Chem of Miner 44:21-31.

519 Schmidt, P., Nash DJ, Coulson S, Göden MB, Awcock GJ (2017c) Heat treatment as a universal 520 technical solution for silcrete use? A comparison between silcrete from the Western Cape (South 521 Africa) and the Kalahari (Botswana). PLoS One 12:e0181586.

522 Steele TE, Mackay A, Fitzsimmons KE, Igreja M, Marwick B, Orton J, Schwortz S, Stahlschmidt MC 523 (2016) Varsche Rivier 003: A Middle and Later Stone Age site with Still Bay and Howiesons Poort 524 assemblages in southern Namaqualand, South Africa. PaleoAnthropol 2016:100-163.

525 Summerfield MA (1981) The nature and occurrence of silcrete, southern Cape Province, South 526 Africa. Vol. 28. School of Geography, University of Oxford.

527 Villa P, Roebroeks W (2014) Neandertal demise: an archaeological analysis of the modern human 528 superiority complex. PLoS One 9:e96424.

529 Wadley L, Prinsloo LC (2014) Experimental heat treatment of silcrete implies analogical reasoning in 530 the Middle Stone Age. J Hum Evol 70:49-60.

531 Wickham H (2007) Reshaping Data with the reshape Package. J Stat Softw 21:1-20.

532 Wickham H (2009) ggplot2: Elegant Graphics for Data Analysis. Springer-Verlag, New York. 
Mackay et al, Variance in the response of silcrete to rapid heating, Arch \& Anth Sci.

533 Wickham H (2017) scales: Scale Functions for Visualization. R package version 0.5.0.

534 https://CRAN.R-project.org/package=scales

535 Young RW, McDougall I (1982) Basalts and silcretes on the coast near Ulladulla, southern New 536 South Wales. J Geol Soc of Aust 29:425-430.

537 
Mackay et al, Variance in the response of silcrete to rapid heating, Arch \& Anth Sci.

538

539

540

541

542

543

544

545

546

547

548

549 Figure captions

550

551

552

553

554

555

556

557

558

559

\section{Table captions} ${ }^{\circ} \mathrm{C}$.
Table 1. Percentage of remaining mass after heating for each of the NSW silcrete samples. White cells=survived; light grey cells=fractured; dark grey cells=exploded. $*$ denotes instances where corresponding samples could not be identified in the furnace after heating.

Table 2. Proportional odds model for the effect of temperature, volume and source on sample heat fracture among the tested NSW silcrete.

Table 3. Sample frequency in each of the three heat fracture categories above and below 573

Table 4. Proportional odds model for the effect of temperature, volume and source on sample heat fracture among the tested NSW silcrete (exclude $1 \mathrm{~cm}^{3}$ samples).

Figure 1. The two hypothesized models of silcrete heat fracture tested in this study.

Figure 2. The locations of silcrete sources in Australia (top) and South Africa (bottom) where the test samples used in this study were collected from.

Figure 3. The distribution of sample heat fracture by volume and heating temperature between the two NSW sources. Blue=Survived; Green=Fractured; Red=Exploded.

Figure 4. The modelled effect of stone volume (exclude $1 \mathrm{~cm}^{3}$ ) on the probability for different degrees of heat fracture between the two NSW sources.

Figure 5. The distribution of sample heat fracture by volume and heating temperature among the three South African sources. Blue=Survived; Green=Fractured; Red=Exploded. 
Mackay et al, Variance in the response of silcrete to rapid heating, Arch \& Anth Sci.

560 Appendix: Proportional odds model for BNS samples only

561 Including $1 \mathrm{~cm}^{3}$ samples

Coefs. Std. error $\mathrm{z}$ value $\quad p$

\section{Predictor}

temperature*

$\begin{array}{llll}-0.11 & 0.15 & -0.76 & 0.45\end{array}$

volume*

$\begin{array}{llll}-0.93 & 0.16 & -5.69 & <.0001\end{array}$

$\underline{\text { Threshold (intercept) }}$

exploded $\mid$ fractured

$\begin{array}{lll}-0.65 & 0.17 \quad-3.82\end{array}$

fractured $\mid$ survived

0.17

0.16

1.06

Nominal test indicates the proportional odds assumption is not violated.

Likelihood ratio test against null model (intercept only): LR stat=37.12; $\mathrm{df}=2 ; \mathrm{p}<.0001$

Hessian condition number $=4.9$

*Transformed to z score

562

Excluding $1 \mathrm{~cm}^{3}$ samples

\section{Coefs. Std. error $\mathrm{z}$ value $p$}

\section{$\underline{\text { Predictor }}$}

temperature*

$\begin{array}{llll}-0.12 & 0.17 & -0.72 & 0.47\end{array}$

volume*

$-0.96$

0.19

$-4.96$

$<.0001$

Threshold (intercept)

exploded | fractured

$-0.77 \quad 0.20$

$-3.76$

fractured $\mid$ survived

0.31

0.19

1.64

Nominal test indicates the proportional odds assumption is not violated.

Likelihood ratio test against null model (intercept only): LR stat=27.77; $\mathrm{df}=2 ; \mathrm{p}<.0001$

Hessian condition number $=4.6$

*Transformed to z score 
Mackay et al, Variance in the response of silcrete to rapid heating, Arch \& Anth Sci.

565

566 

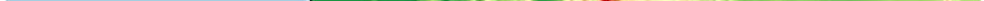


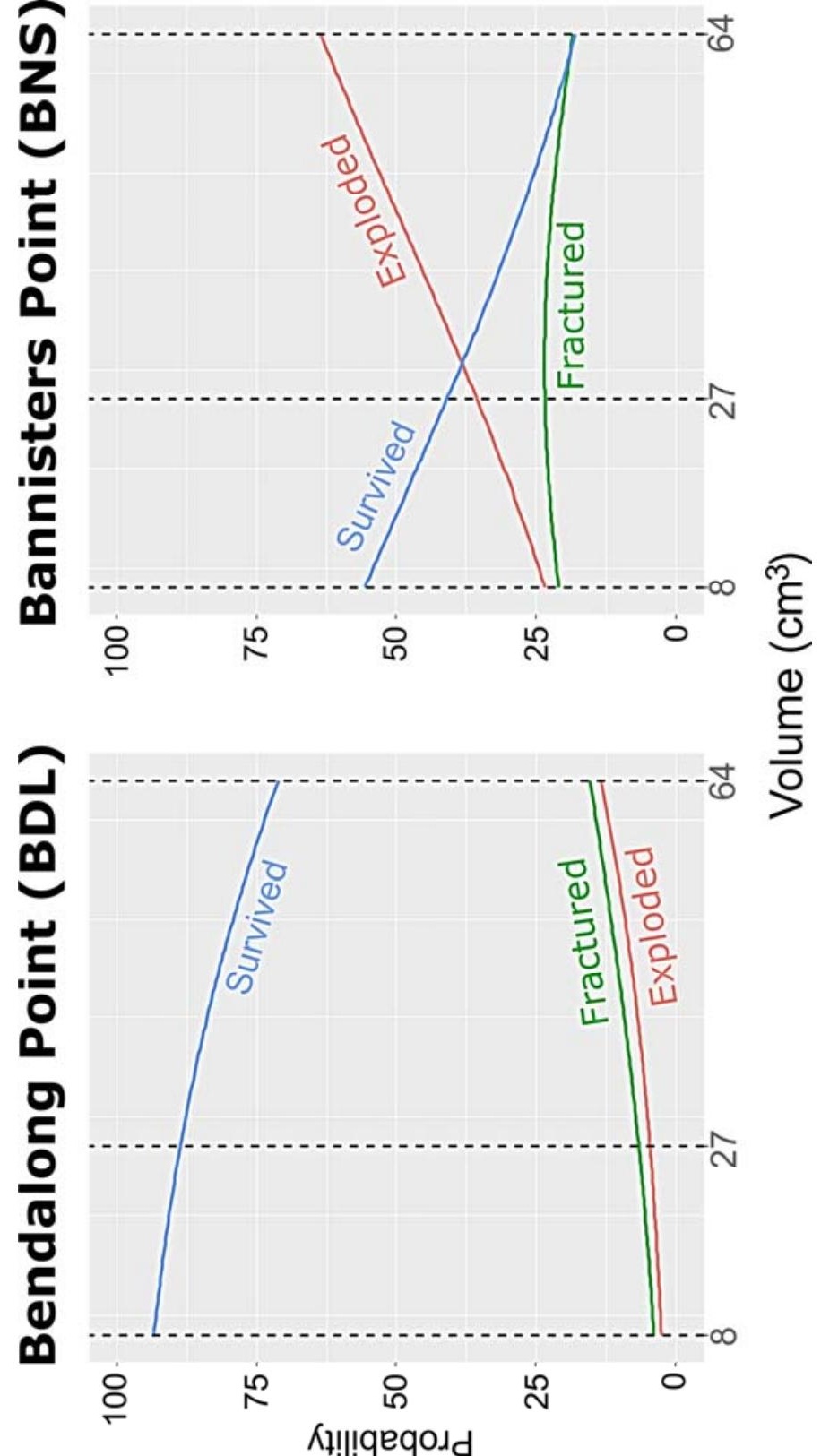




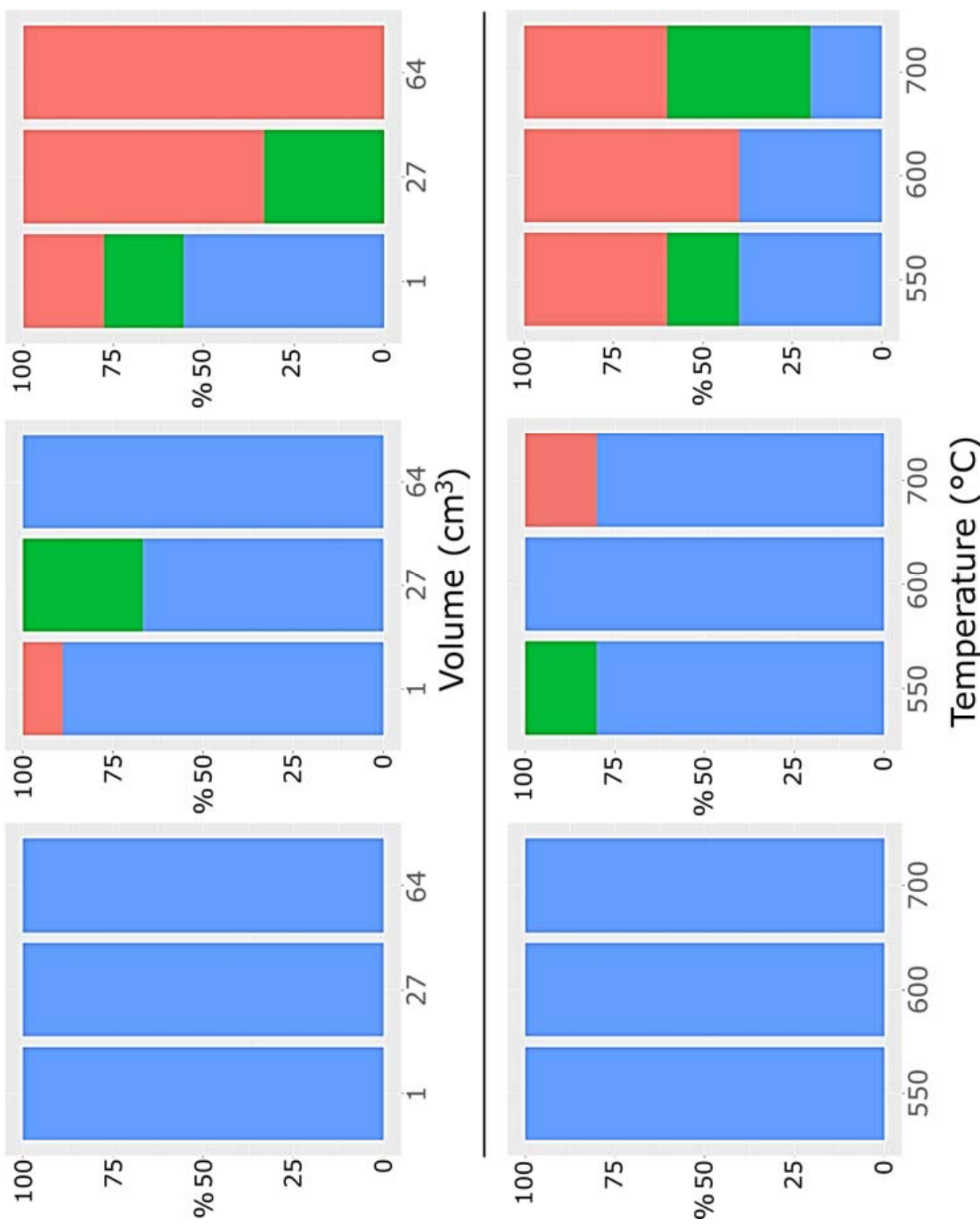




\begin{tabular}{|c|c|c|c|c|c|c|c|c|c|c|c|c|}
\hline \multirow{2}{*}{ Source } & \multicolumn{3}{|c|}{$1 \mathrm{~cm}^{3}$} & \multicolumn{3}{|c|}{$8 \mathrm{~cm}^{3}$} & \multicolumn{3}{|c|}{$27 \mathrm{~cm}^{3}$} & \multicolumn{3}{|c|}{$64 \mathrm{~cm}^{3}$} \\
\hline & 550 & 600 & 700 & 550 & 600 & 700 & 550 & 600 & 700 & 550 & 600 & 700 \\
\hline & ${ }^{\circ} \mathrm{C}$ & ${ }^{\circ} \mathrm{C}$ & ${ }^{\circ} \mathrm{C}$ & ${ }^{\circ} \mathrm{C}$ & ${ }^{\circ} \mathrm{C}$ & ${ }^{\circ} \mathrm{C}$ & ${ }^{\circ} \mathrm{C}$ & ${ }^{\circ} \mathrm{C}$ & ${ }^{\circ} \mathrm{C}$ & ${ }^{\circ} \mathrm{C}$ & ${ }^{\circ} \mathrm{C}$ & ${ }^{\circ} \mathrm{C}$ \\
\hline \multirow{5}{*}{$\begin{array}{c}\text { BDL } \\
\text { Nodule } \\
1\end{array}$} & 98 & 98 & 100 & 100 & 100 & 99 & 100 & 100 & 100 & 100 & 89 & 59 \\
\hline & 98 & 98 & 98 & 99 & 100 & 100 & 100 & 99 & 100 & 100 & 100 & 91 \\
\hline & 100 & 97 & 95 & 99 & 99 & 100 & 100 & 99 & 100 & 100 & 99 & 49 \\
\hline & 100 & 0 & 100 & 99 & 100 & 99 & 100 & 99 & 100 & 100 & 100 & 99 \\
\hline & 98 & 0 & 100 & 0 & 100 & $N A$ & 99 & 100 & 99 & 99 & 100 & 100 \\
\hline \multirow{5}{*}{$\begin{array}{c}\text { BDL } \\
\text { Nodule } \\
2\end{array}$} & 100 & 100 & 100 & 100 & 100 & 100 & 99 & 58 & 34 & 99 & 100 & 68 \\
\hline & 100 & 100 & 0 & 100 & 99 & 73 & 30 & 81 & 99 & 100 & 99 & 99 \\
\hline & 100 & 100 & 98 & 100 & 100 & 96 & 94 & 99 & 99 & 100 & 96 & 56 \\
\hline & 100 & 99 & 0 & 100 & 99 & 100 & 99 & 100 & 99 & 97 & 100 & 99 \\
\hline & 100 & 98 & 100 & 0 & 99 & 88 & 43 & 99 & 98 & 100 & 96 & 99 \\
\hline \multirow{5}{*}{$\begin{array}{c}\text { BDL } \\
\text { Nodule } \\
3\end{array}$} & 98 & 0 & 37 & 99 & 99 & 99 & 99 & 96 & 99 & 52 & 31 & 35 \\
\hline & 100 & 99 & 100 & 99 & 99 & 99 & 99 & 98 & 98 & 38 & 100 & 99 \\
\hline & 91 & 100 & 100 & 100 & 97 & 99 & 98 & 99 & 93 & 47 & 99 & 99 \\
\hline & 100 & 97 & 80 & 99 & 99 & 99 & 99 & 99 & 98 & 99 & 92 & 99 \\
\hline & 100 & 97 & 100 & 0 & 99 & 98 & 100 & 98 & 99 & 99 & 87 & 91 \\
\hline \multirow{5}{*}{$\begin{array}{c}\text { BNS } \\
\text { Nodule } \\
1\end{array}$} & 100 & 100 & 100 & 100 & 53 & 49 & 19 & 74 & 38 & 47 & 64 & $0 *$ \\
\hline & 98 & 100 & 95 & 99 & 100 & 100 & 100 & 100 & 39 & 18 & 36 & $0 *$ \\
\hline & 100 & 98 & 97 & 100 & 100 & 99 & 72 & 51 & 99 & 14 & 12 & $0^{*}$ \\
\hline & 100 & 97 & 100 & 99 & 33 & 100 & 99 & 57 & 100 & 23 & 85 & $0 *$ \\
\hline & 98 & 100 & 100 & 0 & 100 & 89 & 56 & 100 & 22 & 40 & 99 & 38 \\
\hline \multirow{5}{*}{$\begin{array}{c}\text { BNS } \\
\text { Nodule } \\
2\end{array}$} & 96 & 0 & 100 & 96 & 99 & 89 & 85 & 88 & 60 & 21 & 87 & $0^{*}$ \\
\hline & 98 & 0 & 100 & 0 & 81 & 81 & 24 & 99 & 100 & 99 & 25 & $0^{*}$ \\
\hline & 0 & 98 & 95 & 0 & 62 & 99 & 59 & 51 & 86 & 58 & 96 & $0^{*}$ \\
\hline & 98 & 100 & 100 & 91 & 76 & 60 & 57 & 99 & 44 & 26 & 78 & 94 \\
\hline & 97 & 100 & 0 & $N A$ & 0 & 84 & 99 & 40 & 97 & 27 & 92 & $0^{*}$ \\
\hline \multirow{5}{*}{$\begin{array}{c}\text { BNS } \\
\text { Nodule } \\
3\end{array}$} & 100 & 100 & 98 & 99 & 99 & 73 & 99 & 56 & 99 & 78 & 25 & 87 \\
\hline & 0 & 0 & 100 & 100 & 24 & 100 & 28 & 99 & 16 & 15 & 47 & 0* \\
\hline & 100 & 99 & 0 & 99 & 99 & 100 & 25 & 9 & 34 & 99 & 17 & 100 \\
\hline & 98 & 0 & 0 & 99 & 99 & 99 & 99 & 37 & 38 & 49 & 39 & $0^{*}$ \\
\hline & 0 & 0 & 0 & 0 & 100 & 99 & 98 & 100 & 100 & 37 & 28 & 19 \\
\hline
\end{tabular}

2 Table 1. Percentage of remaining mass after heating for each of the NSW silcrete samples.

3 White cells=survived; light grey cells=fractured; dark grey cells=exploded. $*$ denotes

4 instances where corresponding samples could not be identified in the furnace after heating. 


\begin{tabular}{|lcccccc|}
\hline & Coefs. & \multicolumn{2}{c}{ Cross valid. coefs. } & Std. & z value & $p$ \\
& & $5 \%$ & $95 \%$ & error & \\
\hline $\begin{array}{l}\text { Predictor } \\
\text { temperature* }\end{array}$ & -0.15 & -0.36 & 0.065 & 0.12 & -1.21 & 0.23 \\
volume* & -0.27 & -0.64 & 0.081 & 0.20 & -1.39 & 0.16 \\
source (BNS) & -1.85 & -2.42 & -1.43 & 0.26 & -7.06 & $<\mathbf{0 . 0 0 1}$ \\
volume* : source (BNS) & -0.64 & -1.10 & -0.19 & 0.25 & -2.51 & $\mathbf{0 . 0 1 2}$ \\
\hline Threshold (intercept) & & & & & & \\
exploded | fractured & -2.45 & -3.02 & -2.09 & 0.23 & -10.47 & - \\
fractured | survived & -1.71 & -2.19 & -1.40 & 0.21 & -8.09 & - \\
\hline
\end{tabular}

Nominal test indicates the proportional odds assumption is not violated.

Likehood ratio test against null model (intercept only): LR stat. $=98.14 ; \mathrm{df}=4 ; \mathrm{p}<.0001$

Hessian condition number $=28$

*Transformed to z score

7 Table 2. Proportional odds model for the effect of temperature, volume and source on sample 8 heat fracture among the tested NSW silcrete.

9

10 


\begin{tabular}{|l|lll|}
\hline & Survived & Fractured & Exploded \\
\hline Below $573{ }^{\circ} \mathrm{C}$ & $82(68 \%)$ & $8(7 \%)$ & $30(25 \%)$ \\
$\left(550{ }^{\circ} \mathrm{C}\right)$ & & & $53(22 \%)$ \\
Above $573{ }^{\circ} \mathrm{C}$ & $153(64 \%)$ & $33(14 \%)$ & \\
$\left(500{ }^{\circ} \mathrm{C}+600{ }^{\circ} \mathrm{C}\right)$ & & & \\
\hline
\end{tabular}

12 Table 3. Sample frequency in each of the three heat fracture categories above and below 573 $13{ }^{\circ} \mathrm{C}$. 


\begin{tabular}{|lcccccc|}
\hline & Coefs. & \multicolumn{2}{c}{ Cross valid. coefs. } & Std. \\
& & $5 \%$ & $95 \%$ & error & z value & $p$ \\
\hline$\underline{\text { Predictor }}$ & & & & & & \\
temperature* & -0.081 & -0.25 & 0.081 & 0.14 & -0.59 & 0.56 \\
volume* & -0.76 & -0.96 & -0.60 & 0.15 & -5.05 & $<\mathbf{0 . 0 0 1}$ \\
source (BNS) & -2.42 & -2.91 & -2.09 & 0.31 & -7.68 & $<\mathbf{0 . 0 0 1}$ \\
Threshold (intercept) & & & & & & \\
exploded | fractured & -3.07 & -3.58 & -2.54 & 0.31 & -9.86 & - \\
fractured | survived & -2.11 & -2.72 & -1.82 & 0.27 & -7.71 & - \\
\hline
\end{tabular}

Nominal test indicates the proportional odds assumption is not violated.

Likelihood ratio test against null model (intercept only): LR stat=92.82; $\mathrm{df}=3 ; \mathrm{p}<.0001$

Hessian condition number $=27$

*Transformed to z score

16 Table 4. Proportional odds model for the effect of temperature, volume and source on sample

17 heat fracture among the tested NSW silcrete (exclude $1 \mathrm{~cm}^{3}$ samples). 